\title{
Room temperature growth of biaxially aligned yttria-stabilized zirconia films on glass substrates by pulsed-laser deposition
}

\author{
Peng Li, Jason Carroll and Jyoti Mazumder \\ Center for Laser-Aided Intelligent Manufacturing, University of Michigan, Ann Arbor, \\ Michigan 48109-2125, USA \\ E-mail: mazumder@umich.edu
}

Received 8 October 2002, in final form 8 April 2003

Published 18 June 2003

Online at stacks.iop.org/JPhysD/36/1605

\begin{abstract}
Room temperature deposition of biaxially textured yttria-stabilized zirconia (YSZ) films on amorphous glass substrates was successfully achieved by conventional pulsed-laser deposition. The influence of the surrounding gases, their pressure and the deposition time on the structure of the films was studied. A columnar growth process was revealed based on the experimental results. The grown biaxial texture appears as a kind of substrate independence, which makes it possible to fabricate in-plane aligned YSZ films on various substrates.
\end{abstract}

Today yttria-stabilized zirconia (YSZ) films are used widely as buffer layers for growing thin films of high temperature superconductor $\mathrm{YBa}_{2} \mathrm{Cu}_{3} \mathrm{O}_{7-x}$ (YBCO), while pulsed-laser deposition (PLD) is thought of as one of the most technologically versatile and economically acceptable methods for YSZ film growth [1]. Epitaxially grown YSZ films have been achieved successfully on (100) Si and InP substrates using PLD [2-6]. Besides the perfect crystalline substrates, high deposition temperature, generally above $600^{\circ} \mathrm{C}$, is needed for this kind of heteroepitaxial growth. However, for more practical applications, polycrystalline or amorphous substrates and low deposition temperature are needed.

Several groups have attempted to deposit YSZ films as buffer layers on polycrystalline metals or alloys and amorphous glass substrates [7-18]. For these substrates, biaxially aligned YSZ buffer layers, with [100] axis oriented normal to substrates, are needed for high quality in-plane aligned YBCO films growth. In-plane ( $a$ and $b$ axes) alignments have been believed to be a critical factor to reduce the large-angle grain boundaries in YBCO films which will severely suppress the desired high critical currents $\left(J_{\mathrm{c}}\right)[11,12]$.

Currently, ion beam assisted deposition (IBAD) is the most frequently used technique to fabricate biaxially aligned YSZ films on polycrystalline alloys with substrate temperature $\sim 100^{\circ} \mathrm{C}$ [10-12], although the assisted ion bombardment will lead to a relatively slow buffer layer deposition process [13]. Another approach is the so-called inclined-substrate PLD. While biaxially aligned YSZ films have been grown on polycrystalline Hastelloy at room temperature using this method, it was argued that these layers have a columnar microstructure with the columns inclined towards incoming materials $[13,14,19,20]$.

On the other hand, until now attempts on amorphous glass $[15,16,21]$ and fused quartz [22] showed only amorphous YSZ films can be obtained for room temperature deposition. The threshold deposition temperature reported for the appearance of polycrystalline $\mathrm{YSZ}$ is $300-350^{\circ} \mathrm{C}$ for general PLD [21, 22] and even at $600^{\circ} \mathrm{C}$ substrate temperature only uniaxial orientation is exhibited in the films [15]. In our experiments, we found this threshold temperature can be decreased to room temperature if suitable deposition parameters are chosen. We present here the experimental results on growing [100]-oriented and further the biaxially aligned polycrystalline YSZ films on commercial glass substrates by conventional PLD at room temperature.

The PLD system used in the experiments was described elsewhere [23]. Hot pressed $\mathrm{ZrO}_{2}$ target (PureTech Inc., stabilized with $5 \mathrm{wt} \% \mathrm{Y}_{2} \mathrm{O}_{3}$ ) was enclosed in a stainless-steel vacuum chamber with the background vacuum in $10^{-6}$ Torr. $\mathrm{KrF}$ excimer laser $248 \mathrm{~nm}$ (Lambda Physik, EMG 201) ran at $10 \mathrm{~Hz}$ with the pulse width $\sim 20 \mathrm{~ns}$. The laser beam hits the target at $\sim 40^{\circ}$ angle of incidence and the income beam was focused to a $3 \mathrm{~mm}^{2}$ area with its energy fluence at $2 \mathrm{~J} \mathrm{~cm}^{-2}$. Fisherbrand cover glass (Fisher Scientific International Inc.) was degreased and cleaned using acetone before being used as a substrate. The distance between the ablation point and 
the centre of the substrate is $\sim 2 \mathrm{~cm}$. X-ray diffraction (XRD), rocking curve and pole figure measurements were performed on Rigaku Rotaflex and scanning electron microscopy (SEM) and energy dispersive spectrometer (EDS) on a Philips XL30 set-up, respectively.

Figure 1 plots the results of the XRD $\theta / 2 \theta$ scan of YSZ films deposited at base vacuum and different oxygen pressure for $30 \mathrm{~min}$. Cubic system was used to index the peaks because it is difficult to determine the exact one between tetragonal and cubic crystal structure based on the XRD results here. It can be clearly seen that the films grown at the oxygen pressure less than 0.02 Torr show a strong preferential orientation along [100] direction. This orientation phenomenon was observed before [24] and thought as somewhat substrate independent. Phases other than cubic or tetragonal appeared at 0.01 Torr with the appearance of a new peak near $25^{\circ}$, which can be clearly seen in the log-plots, figure $1(b)$.

(a)

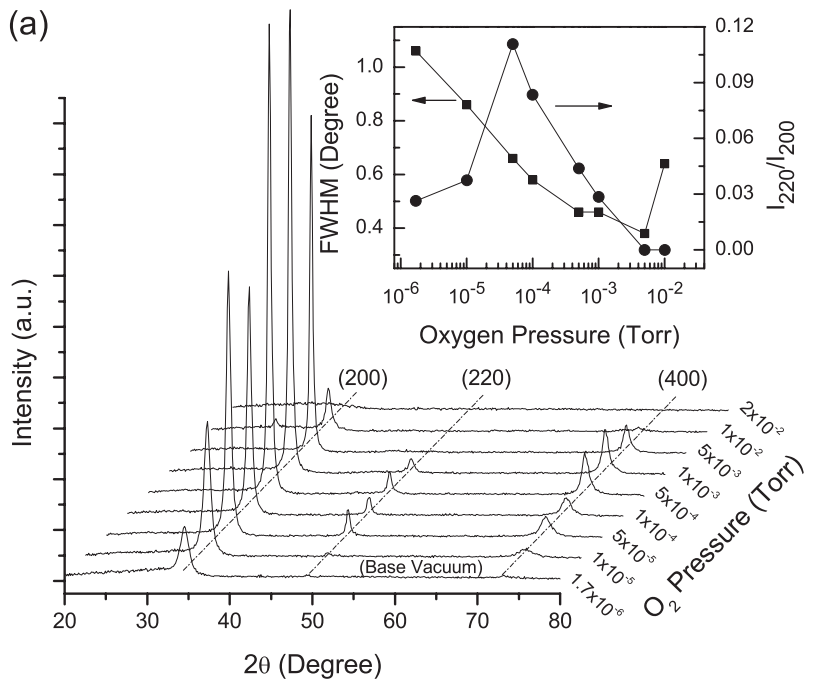

(b)

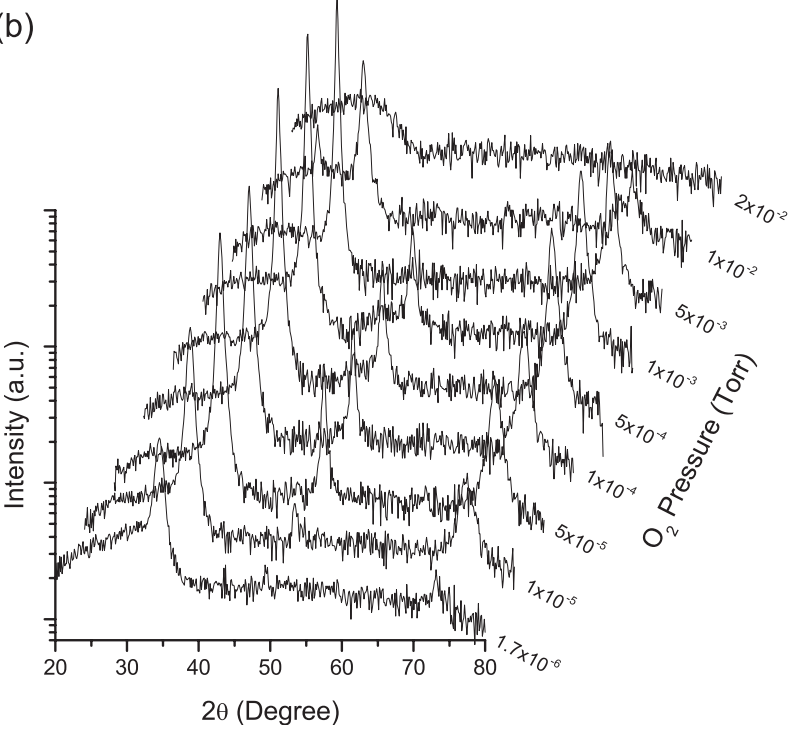

Figure 1. (a) XRD $\theta / 2 \theta$ scan of the YSZ films deposited at different oxygen pressure. The one grown at the base vacuum is also presented. The inset shows the variation of FWHM of (200) peaks and intensity ratio between (220) and (200) peaks. (b) Log-plots of the XRD spectra.
From base vacuum, with the increase of the oxygen pressure, a (220) peak appeared, reached its maximum intensity at around $5 \times 10^{-4}$ Torr and then decreased and vanished above $1 \times 10^{-3}$. Meanwhile, the full-width at halfmaximum (FWHM) of (200) peak reduced from $1.06^{\circ}$ at base vacuum to $0.38^{\circ}$ at $5 \times 10^{-3}$, which indicated better crystalline structure formed in the films. The optimal oxygen pressure for [100]-oriented YSZ films with no [220] peaks was found around $3 \times 10^{-3}$ Torr in our experiments. The rocking curve FWHM of the (200) peaks was around $6 \pm 0.5^{\circ}$ and showed little dependence on the oxygen pressure used. This FWHM value is similar to the reported IBAD films on glass [16] and much better than that on pyrex glass [15].

The broadening of (200) XRD peaks of the films grown at base vacuum and low oxygen pressure, see the inset in figure 1(a), may be caused mainly by two factors, small crystal grains (in the order of $10 \mathrm{~nm}$ ) or lattice distortion due to the oxygen deficiency which was confirmed by our EDS measurements. Oxygen content was about 55.9 at $\%$ for the films grown at base vacuum while the calculated value from $\mathrm{ZrO}_{2}+5 \mathrm{wt} \% \mathrm{Y}_{2} \mathrm{O}_{3}$ stoichiometry formula is around 66.3 at\%. Oxygen deficiency was decreased with increasing oxygen pressure and was overcome with pressure higher than about $2 \times 10^{-4}$ Torr.

To clarify the influence of the oxygen deficiency on film structures, a series of YSZ films were prepared in argon atmosphere using the same deposition conditions as were used previously. The corresponding spectra of XRD scan are plotted in figure 2. Compared with the samples listed in figure 1, the films grown in argon have a broader (200) XRD peak with weak-pressure-dependent FWHM at $\sim 0.9^{\circ}$. We found similar broad (200) peaks also reported in the YSZ films grown on different substrates, even [001]-oriented single-crystal Si wafer, under substrate bias assistance in $1.5 \times 10^{-3}$ Torr argon atmosphere ([17] and references therein, [18]).

SEM was used to check the thickness and grain structures in the experiments. Figure 3 shows three cross-section SEM images of YSZ films with different growth conditions. Thickness of the films was found in the range from $\sim 0.6$ to $\sim 1 \mu \mathrm{m}$, for $0.5 \mathrm{~h}$ deposition, depending on the growth parameters. Film thickness increases with the increase of gas pressure when an oxygen atmosphere is used while keeping to about $0.6-0.7 \mu \mathrm{m}$ for different argon pressures below 0.02 Torr.

From figure 3, clear columnar grains can be seen in spite of different gas pressure and atmosphere used. At the same time the lager grain size, in hundreds of nanometre, near the film surface suggests grain size will not give the major contribution in broadening of (200) XRD peaks plotted in figures 1 and 2 . Thus, the lattice distortion due to the oxygen deficiency should be the main reason for the broadening. This also explains why the films deposited in argon show the pressure-insensitive broad (200) peaks. Although the set-up used for deposition in this paper is a kind of inclined-substrate system [23], and the samples were cut along the direction of the arriving species for cross-section observation, tilted columnar grain growth, as mentioned in $[13,14,20]$, was hardly seen.

In-plane orientation of the films was studied by measuring $\mathrm{x}$-ray pole figures of the (111) YSZ peaks, as shown in figure 4. The direction from which the deposited particles arrived was 
(a)

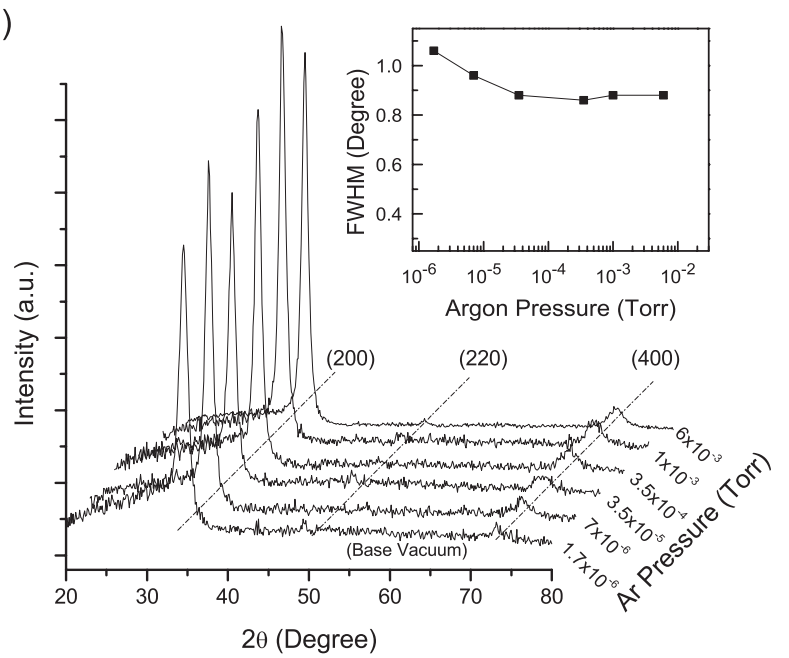

(b)

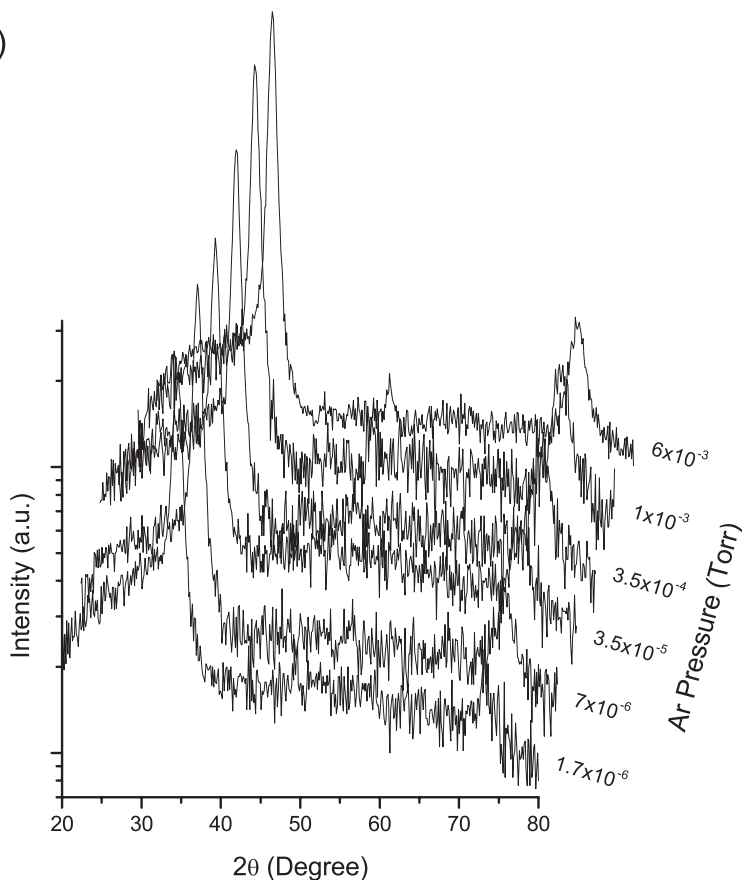

Figure 2. (a) XRD $\theta / 2 \theta$ scan of the YSZ films deposited at different argon pressure. The one grown at the base vacuum, same as that used in figure 1, is also presented. The inset shows the variation of FWHM of (200) peaks. (b) The corresponding log-plots.

aligned with $0^{\circ}$ on the pole figure. For $0.5 \mathrm{~h}$ deposition, no inplan alignments existed in the sample grown in base vacuum, figure 4(c), while some kinds of order appeared in the films grown in oxygen, figure 4(a). After increasing the deposition time, biaxial alignment formed in both films, figures $4(b)$ and $(d)$. The influence of the deposition time on in-plane orientation indicates the process of the columnar growth and organization of the grains in YSZ films. In our experiments, film with short time deposition, $5 \mathrm{~min}$, at base vacuum was also checked by XRD and was found to be amorphous. The FWHM of azimuthal angle for (111) signals were around $40^{\circ}$ and $45^{\circ}$ in figures $4(b)$ and $(d)$, respectively. These values are not as good as the reported $25^{\circ}$ of the IBAD films on glass [16]. Quinton et al [14] has studied the dependence of the in-plane alignment on film thickness in inclined-substrate PLD. With

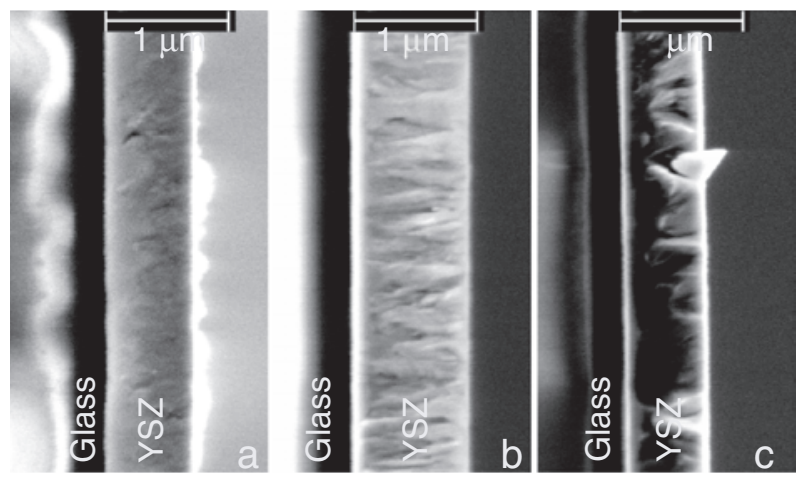

Figure 3. Cross-section SEM images of YSZ films deposited at (a) $5 \times 10^{-5}$ Torr, $\mathrm{O}_{2},(b) 4 \times 10^{-3}$ Torr, $\mathrm{O}_{2}$, and $(c) 7 \times 10^{-6}$ Torr, Ar. Deposition time is $0.5 \mathrm{~h}$ for all three samples.
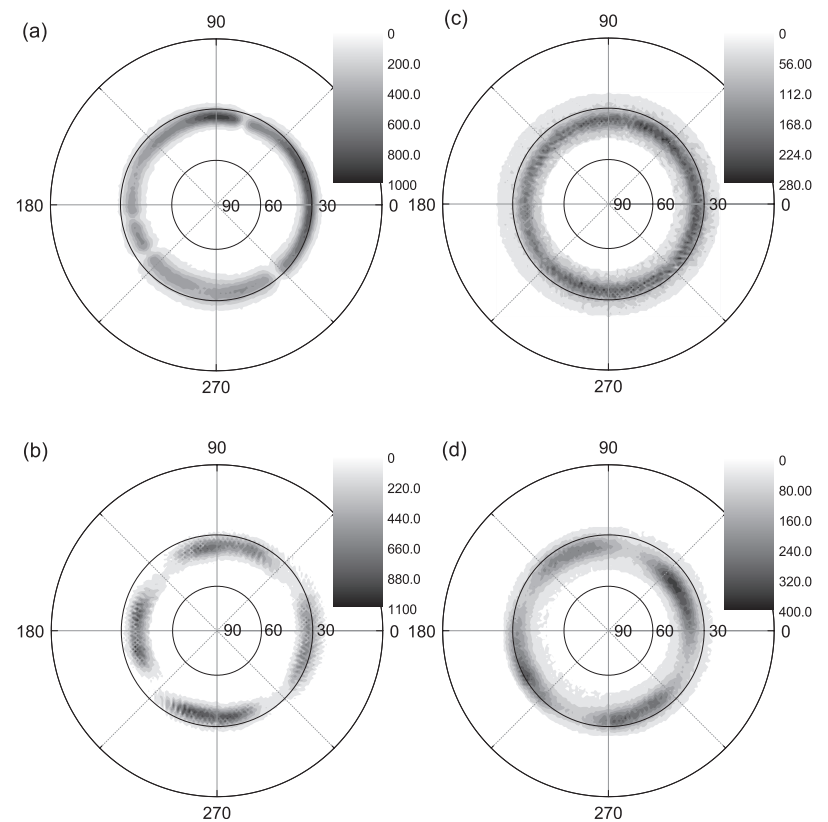

Figure 4. X-ray pole figures of YSZ thin films, (111) peak, deposited at $(a) 3 \times 10^{-3}$ Torr, $\mathrm{O}_{2}$, for $0.5 \mathrm{~h},(b) 3 \times 10^{-3}$ Torr, $\mathrm{O}_{2}$, for $2 \mathrm{~h},(c) 1.7 \times 10^{-6}$ Torr, base vacuum, for $0.5 \mathrm{~h}$, (d) $1.7 \times 10^{-6}$ Torr, base vacuum, for $1.5 \mathrm{~h}$.

the films deposited on inclined Hastelloy substrates, they found the FWHM of the YSZ (111) pole figure peaks decreased with increasing film thickness, from $\sim 35^{\circ}$ for $1.5 \mu \mathrm{m}$ films to $\sim 20^{\circ}$ for $4 \mu \mathrm{m}$, and the final YBCO films grown epitaxially on those YSZ buffer layers were even better aligned than the YSZ. The facts were explained using columnar growth mechanism [14].

All these experimental results sketch out the process of the film growth. At the beginning of deposition, an amorphous layer was formed on the surface of the substrate, then columnar grains appeared and grew larger and larger, and finally became the biaxially textured film. The growth of oriented polycrystalline YSZ films at room temperature is believed to be contributed mainly from the bombardment of the ions in the ablation plume. When suitable laser pulse energy, substrate-target distance and gas pressure are used, the high speed particles, generally $10^{3}-10^{4} \mathrm{~m} \mathrm{~s}^{-1}[17$, 23 ], in the plume can be utilized as a good source of bombardment. Thus, good quality polycrystalline YSZ films 
can be deposited by conventional PLD without IBAD. Though no tilted columnar growth can be confirmed in our experiments, the off-normal plume for deposition due to the inclinedsubstrate may still be the drive of the formation of the in-plane orientation [14].

Because of the formation of the amorphous layer on the substrate first, the above growth mechanism can be somewhat substrate independent. In fact, silicon wafers were also used as substrate to deposit YSZ films at room temperature in our experiments and similar results were achieved as those on glass substrates.

In summary, successfully growing of in-plane aligned YSZ films on glass substrates using conventional PLD at room temperature was demonstrated. The revealed columnar growth process is likely substrate independent, which makes it possible to fabricate biaxially aligned YSZ films on different substrates.

\section{References}

[1] Sheth A, Schmidt H and Lasrado V 1998 Appl. Supercond. 6855

[2] Fork D K, Fenner D B, Connell G A N, Phillips J M and Geballe T H 1990 Appl. Phys. Lett. 571137

[3] Pechen E V, Schoenberger R, Brunner B, Ritzinger S, Renk K F, Sidorov M V and Oktyabrsky S R 1993 J. Appl. Phys. 743614

[4] Bardal A, Matthee T, Wecker J and Samwer K 1994 J. Appl. Phys. $\mathbf{7 5} 2902$

[5] Wang S J and Ong C K 2002 Appl. Phys. Lett. 802541

[6] Vasco E, Vazquez L, Aguilo M and Zaldo C $2000 \mathrm{~J}$. Cryst. Growth 209883
[7] Kumar A, Ganapathi L, Kanetkar S M and Narayan J 1990 Appl. Phys. Lett. 572594

[8] Kumar A, Ganapathi L, Kanetkar S M and Narayan J 1991 J. Appl. Phys. 692410

[9] Reade R P, Mao X L and Russo R E 1991 Appl. Phys. Lett. 59739

[10] Reade R P, Berdahl P, Russo R E and Garrison S M 1991 Appl. Phys. Lett. 612231

[11] Iijima Y, Tanabe N, kohno O and Ikeno Y 1992 Appl. Phys. Lett. 60769

[12] Iijima Y, Onabe K, Futaki N, Tanabe N, Sadakata N, kohno O and Ikeno Y 1993 J. Appl. Phys. 741905

[13] Quinton W A J and Baudenbacher F 1997 Physica C 292243

[14] Quinton W A J, Liang W Y, Baudenbacher F, Foord D T, Bramley A P and Newcomb S B 1999 IEEE Trans. Appl. Supercond. 91498

[15] Sonnenberg N, Longo A S, Cima M J, Chang B P, Ressler K G, McIntyre P C and Liu Y P 1993 J. Appl. Phys. 74 1027

[16] Chen K Y, Salamo G J, Afonso S, Xu X L, Tang Y Q, Xiong Q, Chan F T and Schaper L W 1996 Physica C 267355

[17] Voevodin A A, Jones J G and Zabinski J S 2001 Appl. Phys. Lett. 78730

[18] Voevodin A A, Jones J G and Zabinski J S $2001 \mathrm{~J}$. Vac. Sci. Technol. A 191320

[19] Hasegawa K et al 1997 Advances in Superconductivity IX ed S Nakajima and M Murakami (Tokyo: Springer) p 745

[20] Denul J, De Winter G and De Gryse R 2001 Physica C 35145

[21] Kokai F, Amano K, Ota H, Ochiai Y and Umemura F 1992 J. Appl. Phys. 72699

[22] Hanus F and Laude L D 1998 Appl. Surf. Sci. 127-129 544

[23] Li P, Lim D and Mazumder J 2002 J. Appl. Phys. 92666

[24] Sankur H, Denatale J, Gunning W and Nelson J G 1987 J. Vac. Sci. Technol. A 52869 